\title{
Groundwater dynamics in Ennuhud Basin, Kordofan Region, Sudan
}

\section{Asim A. Elmansour ${ }^{1 *}$, Elnazir G. Elseed ${ }^{2}$}

${ }^{1}$ Department of Geology, Faculty of Science, University of Kordofan, Elobeid 51111, Sudan

${ }^{2}$ Secretary for Academic Affairs, Colledge of El Imam El Hadi, Umdurman 11112, Sudan

Corresponding Auther Email: umdaballo63@gmail.com

https://doi.org/10.18280/eesrj.050403

Received: 19 October 2018

Accepted: 3 December 2018

\section{Keywords:}

Ennuhud basin, groundwater fluxes, hydraulic gradient, hydraulic parameters, rechadge

\begin{abstract}
The study aims to deduce the physical and hydraulic characteristics of the aquiferous horizons, the dynamism and recharge potentialities of groundwater in En Nuhud basin. Geological, hydrogeological and pumping test observations were used to achieve the mentioned objectives. A complex flow direction imply a regional trend from north to the south with hydraulic gradient about $\left(1.4^{*} 10^{-4}\right)$, but varied local flow directions and hydraulic gradients are also observed. Groundwater fluxes show that the water in the basin circulates with some hydrogeological bodies within the Basement in the western part. Confined aquifers are characterized by weak confining pressure; very small rising of water level above the saturation limits in many wells is recorded. The values of hydraulic conductivity assign that the dominant size in the aquifer material is the coarse sand, followed by fine sand size, then medium sand and lastly the gravel size. Transmissivity obtained from the tested wells ranges from v. high to medium. The sources of recharge to the aquifer system are from the boundary of the basin, the seepage below the surface water courses and recharge potentials through weak zones along fractures dissecting the area. Based on many observations on the water levels in boreholes presently safe abstraction from the basin is assumed. High regulated work and precisely performed process in the future is required to answer the question of the water balance in the area.
\end{abstract}

\section{INTRODUCTION}

The study area is located in west-central Sudan and extends within Kordofan Region between longitudes $28^{\circ} 15^{\prime}$ and $30^{\circ} 00^{\prime} \mathrm{E}$, and latitudes $12^{\circ} 22^{\prime}$ and $13^{\circ} 28^{\prime} \mathrm{N}$ (Figure 1). The area is gently undulated plain with some stabilized sand dunes and isolated ridges and mounds. Most of the area is covered by sand sheets and low dune complexes.

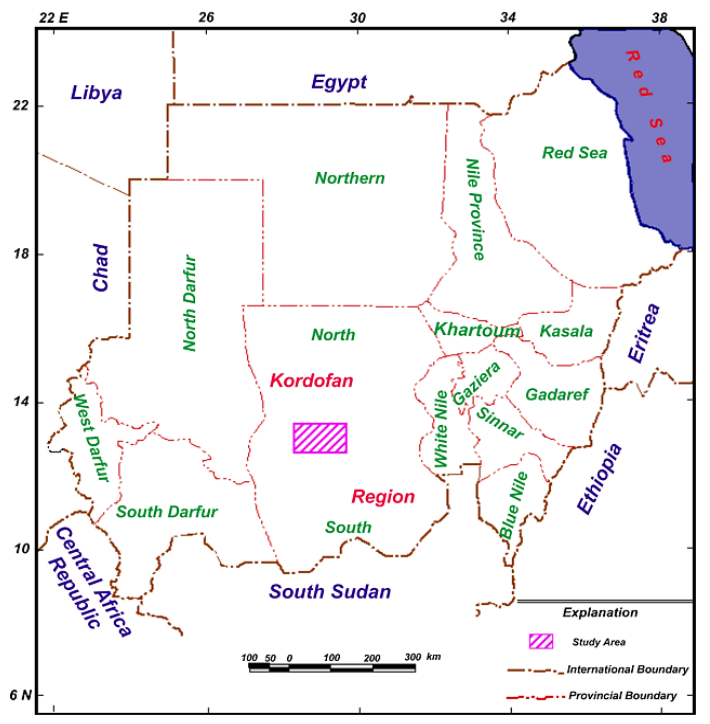

Figure 1. Location map of the study area
Clayey or silty soils and fluvio-lacustrine deposits cover some depressions and the flood plains of water courses in the area. Generally the surface soils are characterized by relatively high permeability which results in a coarse drainage pattern (Figure 2). The surface over most of the area ranges between (538) and (660) meters above the mean sea level (Figure 3), and the basin area is relatively elevated over the surroundings [2].

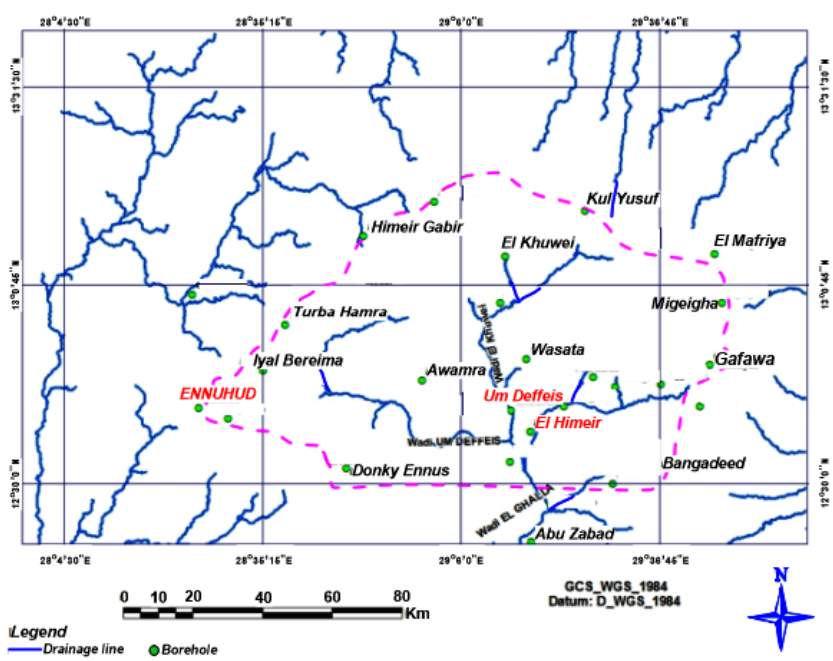

Figure 2. Drainage in the study area 
Many hydrogeological studies were conducted including the study area, the more important of which are: Rodis et al., Karkanis B.G., Strojexport, Ginaya, Ginaya and Elmansour $[2,4-7,17]$. In these studies groundwater resources were assessed and structural setting and tectonic characteristics of the basin were described. Groundwater dynamics in Ennuhud basin has been adressed in some research papers but they are either low detailed or weakly analized. The current research is a contribution in building a scientific base for groundwater development in the area. Fieldwork in addition to archive data from rellavent agencies and individuls represent the base for this research.

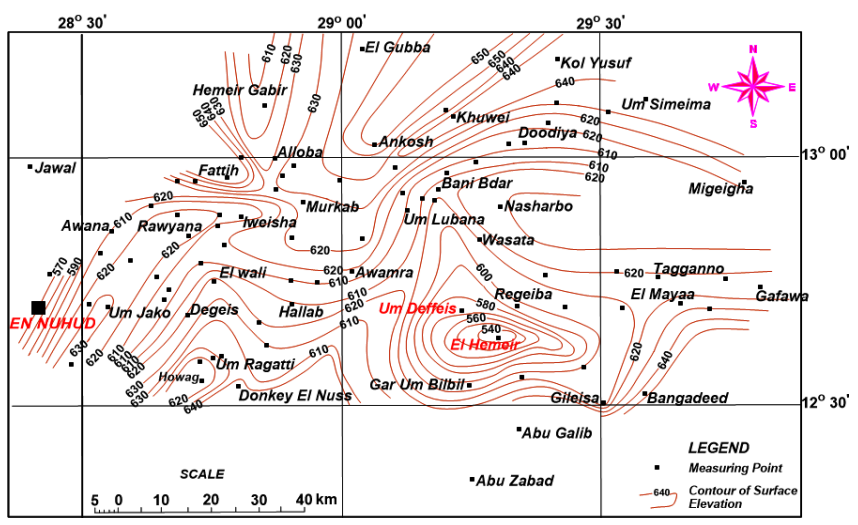

Figure 3. Surface topography contours

\section{SCOPE AND JUSTIFICATIONS OF THE STUDY}

The study aims to deduce the physical characteristics of groundwater environment in the study area. It deals with the physical and hydraulic characteristics of the aquiferous horizons and the dynamism of groundwater in En Nuhud basin; along with the probable recharge potentialities.

\section{METHODOLOGY}

To achieve the mentioned goals many investigations were performed and data from different sources were collected, to find out the groundwater conditions and behavior. In so manner, geological, hydrogeological and pumping test observations were used. Geological observations focus on the rock types, characteristics and extensions, in addition to structural features and their hydrogeological significances. Correcting or measuring locations aims to correct the locations of the hydrogeological features for perfect horizontal correlation. Ground surface elevations were measured in selected points referenced to sea level to be used in vertical correlation of different hydrogeological characteristics. Measurements from pumping test experiments in (38) selected boreholes were analyzed and interpreted. In addition to that data from (212) boreholes reports collected from the relevant institutions and agencies and practitioners were studied and assessed. Accordingly groundwater levels were examined in contrast to mean sea level and a water table contours were constructed.

\section{GEOLOGY}

\subsection{Rock units}

The older rocks in the study area are the rocks of the Basement Complex, at depths range from few meters to more than thousand meters $[4,18]$. The dominant Basement rocks include: gneisses, schists, quartzites, and some intrusive igneous rocks (Figure 4) [12]. Sometimes the Basement Complex is weathered; the thickness of the weathering zone is thicker when the Basement Complex is close to a water saturated body.

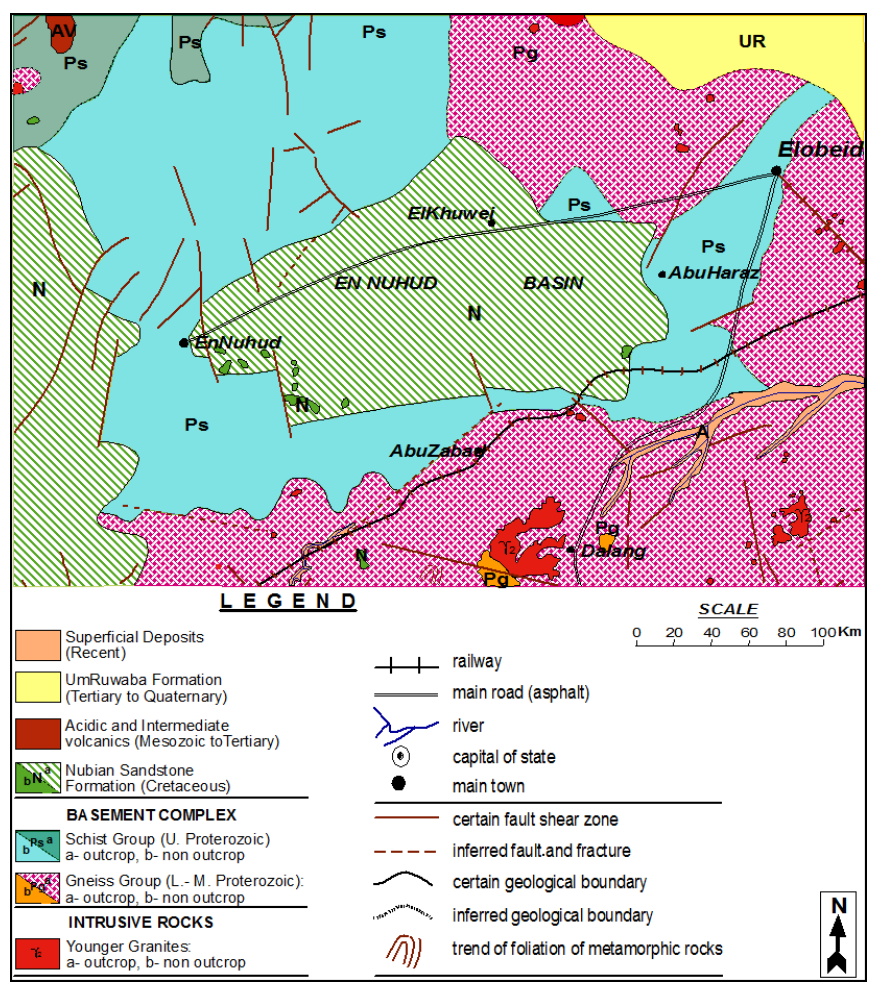

Figure 4. Geology of the area (after G.M.R.D, Sudan, 1981)

Nubian Sandstone Formation unconformably overlay the Basement Complex. It is usually veneered by the recent deposits, but there are some outcrops. Two lithological facies represent the Nubian Sandstone in the area; the pelite-aleurite facies (grain size $<0.05 \mathrm{~mm}$ ) and psamite-psephite facies (grain size > 0.05) [12]. The thickness of the Nubian Sandstone ranges from few to hundred meters. Horizontally the layers are usually discontinuous due to intensive faulting and displacing, hence it is difficult to correlate the geologic units for a long distance (Figure 5).

The dominant lithological units are conglomerates, sandstones and mudstones. Conglomerates and sandstones are usually poorly cemented by clay, silt or iron oxides. Breccias occur in some parts, possibly due to crushing along fault zones, but no remarked beds present. Laterites are present in the weathered zone near the surface at the western margin of the area.

Superficial Deposits covers the older formations in the study area and they mainly of "Qoz Sands, wash deposits and fluvial sediments. Qoz Sands are typical Aeolian sediments of well rounded quarts grains, forming gently-rolling sheets or fixed dunes. Sands, gravels, clays and loam develop in water courses. Generally the Superficial Deposits ranges in thickness from few meters to about 50 meters [2]. 


\subsection{Structures}

En Nuhud basin is a rift basin, with its long side in the direction E-W; it is a fault-bounded depression produced by intensive faulting. The basin is tightly controlled mainly by two sets of faults trending NNW-SSE and E-W ( Figure 6), and intersected by an angle of about $60^{\circ}$; NE or ENE set of fractures is found but it seems to be of a limited effect on the general architecture of the basin.

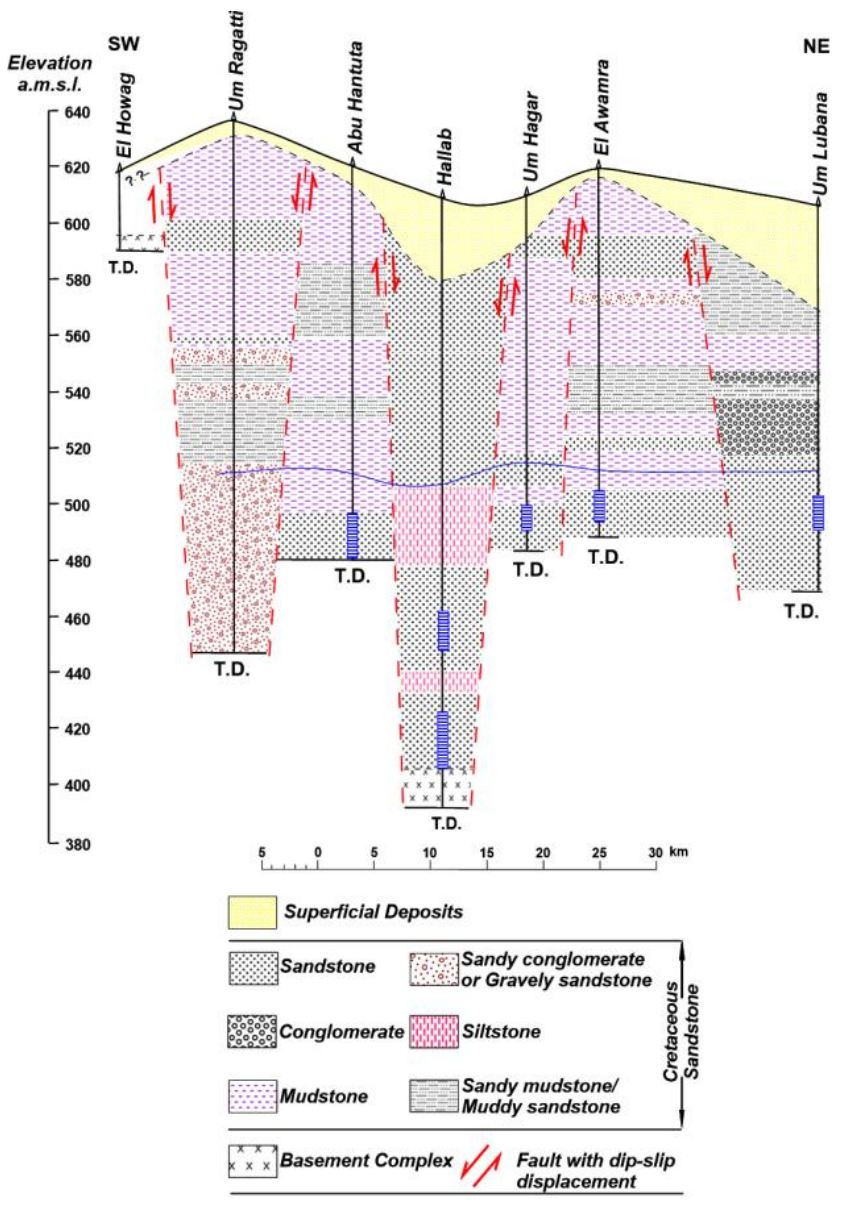

Figure 5. Thickness and discontinuity of the rock units

The intersection of these faults led to formation of polygonal depressions and elevated rock blocks, in turn this situation also mark the whole figure of the basin [2].

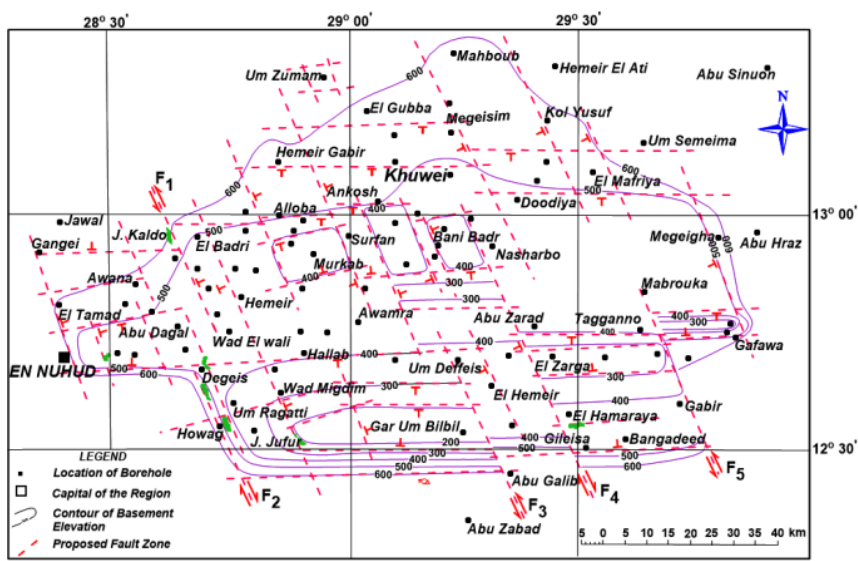

Figure 6. Morphology of the Basement Complex and the dominant Structures [2]

\subsection{Groundwater occurrence}

The main and hydrogeologically important geological unit in the study area is the Nubian Sandstone Formation. The lithological classes within this formation vary in their importance as water bearing environment according to their genetic lithology characteristics, composition, structure and texture. Conglomerates and sandstones represent the main distinguishable aquifers in the study area. Basement Complex can serve as water bearing formation when it is weathered enough to form secondary porosity [17].

The total depth of productive wells ranges from 90 to 410 $\mathrm{m}$. No perched water is recorded in the study area due to the high permeability of the top formation (the Qoz sands) [7]. The thickness of the aquiferous zone obtained from borehole data ranges from 10 to $65 \mathrm{~m}$, but thickness up to $140 \mathrm{~m}$ is revealed by geophysical work in Hydoub area, north Ennuhud town [2].

The aquifers in the study area are classified into two categories: unconfined aquifers which mainly occupy the northern half of the area, and confined aquifers (including semi-confined type) in the southern part (Figure 7). Some parts within the basin confining or unconfining conditions are not clearly distinguished, this exists when the geology is more complex or the available geological data is not sufficient [2]

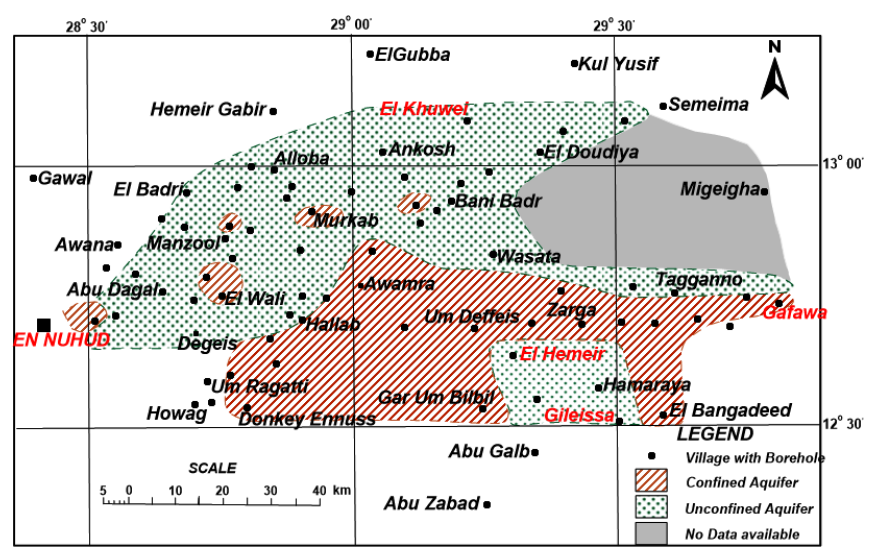

Figure 7. Aquifers classification [2]

\section{RESULTS}

\subsection{Groundwater fluxes}

Water table contours show that the elevation of water table generally ranges between $550 \mathrm{~m}$ in the north to $470 \mathrm{~m}$ in the southeast (Figure 8). Groundwater level contours provide qualitative information concerning the hydraulic conductivity contrasts. The flow direction in the study area show a high complexity, it is generally gives a sense of a regional trend of groundwater flow directed from north to the south with hydraulic gradient about $\left(1.4 \times 10^{-4}\right)$, but varied local flow directions and hydraulic gradients are also observed.

There are some groundwater mounds, the prominent of which are at the north-western part of the area (east of Um El Badri) and at the north-central part (Bani Badr- Murkab). These mounds are interpreted as formed by the excessive seepage below the surface water courses into the aquifer system, or due to recharge potentials through weak zones along fractures dissecting the area. 


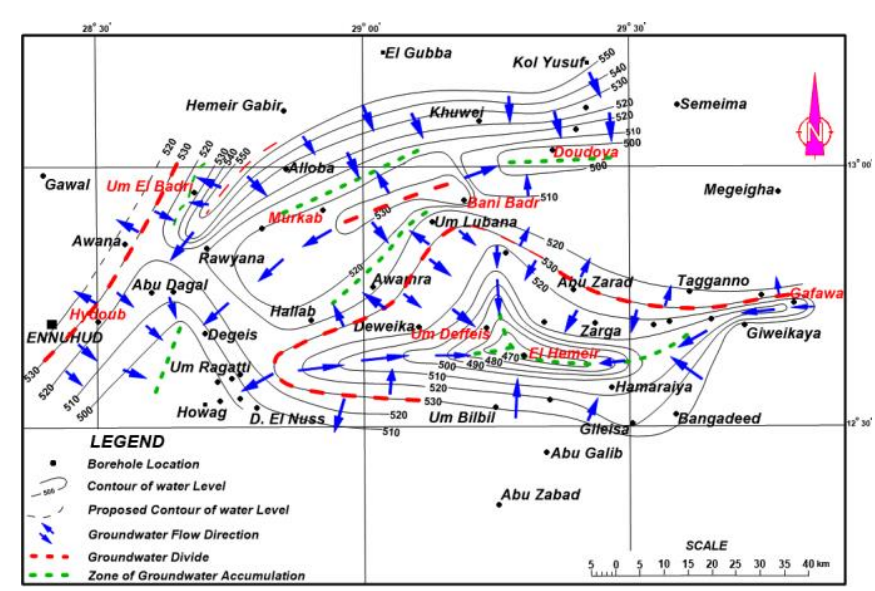

Figure 8. Water table elevations and groundwater fluxes

Also troughs are observed at north-west (El Doodiya) and at the south-east (Um Deffeis- El Himeir); these troughs are interpreted as generated due to either an excessive withdrawal in the area and/or due to local hydrogeological conditions. Regarding to Um Deffeis-El Himeir area, the second assumption is seemed to be the more reliable one in case of that:

- This area is characterized by the shallowest saturated zone within the sedimentary sequence in the area; boreholes with total depth 90-96 m in Um Deffeis (one borehole attend to $136 \mathrm{~m}$ ), and $110 \mathrm{~m}$ in El Himeir.

- The hydraulic gradient was observed to be steeper around this area, which receives recharge from all sides (Figure 8). The great hydraulic gradient is an indication of greater energy losses; meaning greater hydraulic resistance; compared to relatively small hydraulic conductivity.

- The area is represented by the lowest ground surface elevations; it is $577 \mathrm{~m}$ and $472 \mathrm{~m}$ above mean sea level for Um Deffeis and El Himeir respectively (Figure 3), in addition to relatively thick Superficial Deposits (Figure 9).

- It is placed on strike-slipped block, (Figure 6).

- It is characterized by relatively intense drainage (Figure 2).

- Generally this area usually appears as a discriminating unit, for example flow direction shows some deviations at the boundary of the area, according to that means a change in hydraulic conductivity occurs which related to change in lithological characteristics.

Water table contour map (Figure 8) show that within the sedimentary basin there is flow of groundwater directed to the west and southwest away from the boundary of the basin with the Basement Complex. So an assumption of presence of structural conduits between the sedimentary body of En Nuhud basin and the Basement Complex can be agreeable, especially when we consider the fact that there is no hydraulic connection between En Nuhud basin and suqa' El Gamal Basin to the west, as it is stated by Strojexport [12] This means that groundwater in En Nuhud basin circulates with some hydrogeological bodies within the Basement.

\subsection{Pumping tests and hydraulic parameters}

Pumping test experiments in a number of wells that collected from different sources were analyzed, the goal of which is to determine the performance characteristics of the wells and to estimate the hydraulic properties of the aquifer system. Pumping test data collected from 50 recent drilled wells in the study area is evaluated and refined and then 38 of them were selected and adopted for solution. The selection based on the reliability and rationality of the pumping test measurements and the sample distribution.

The pumping test data is evaluated according to the critical factors that may affect the quality of the measurements during the experiment and so the final results, the most important of these factors are:

- Off-site groundwater use during the pumping test, a complicated condition which is difficult to be monitored.

- Geological conditions around the tested well and saturated zone, such as lithologic contacts, aquifer boundaries and leaky conditions that may distort the test measurements.

- Carefully controlling and monitoring the flow rate to avoid fluctuation in the flow rate and hence in water level.

- Accuracy of simultaneous measuring of depth to water and time.

- $\quad$ Time duration of the pumping where long duration is recommended.

As a result some pumping test records were rated to be bad or inaccurate. Stability of readings occurring during the early times of some tests where no leaking effect is expected and jumping in reading values may be due to change in the pumping rate. All of these defects confirm bad monitoring for the test activities especially in the aspect of maintaining the pumping rate. Another note is that the practitioners usually not take care of many factors when designing and implementing pumping test experiments, in case that the objective of most experiments is testing the well performance. Some remarks can be stated concerning the analyzed pumping test data:

- $\quad$ All the data recorded from single- well test type.

- The pumping test data represent constant-discharge and recovery test.

- All Boreholes are examined for short time duration, where the duration time for most tests ranges from 85 to 240 min.; only seven boreholes were examined for a periods range from 280 to $420 \mathrm{~min}$.

- $\quad$ Discharge during the experiments ranges from 3.27 to $22.73 \mathrm{~m}^{3}$, only one borehole in Hydoub area is discharged by $87.27 \mathrm{~m}^{3}$.

- Many of the water bearing formations are partially penetrated by drilling.

- In most boreholes only a short length of the aquifer is screened, in some cases not more than $30 \%$.

- Mostly drawdown is very small.

Under the above mentioned conditions the hydraulic parameters were estimated using computer software. AQTESOLV, Version 3.01.004 standard, software is used and many methods were applied including: Theis (1935), Cooper-Jacob (1946) and Papadopulos-Cooper (1967) for confined aquifer solutions, and Theis (1935), Cooper-Jacob (1946), Neuman (1974), Quick Neuman, Streltsova (1974) and Moench (1997) for unconfined aquifer solutions.

Computer analysis software is used with caution since it is possible to have a good fit of data but assume unreasonable aquifer conditions. The appropriate analysis methods are 
determined based on the aquifer conditions whether it is confined, unconfined or semi-confined, this is determined from the bore $\operatorname{logs}$ or the aquifer responses to pumping, where the plotted data from an aquifer test may indicate which aquifer condition exists. The analysis is revised many times using many methods to obtain reliable or more accurate results.
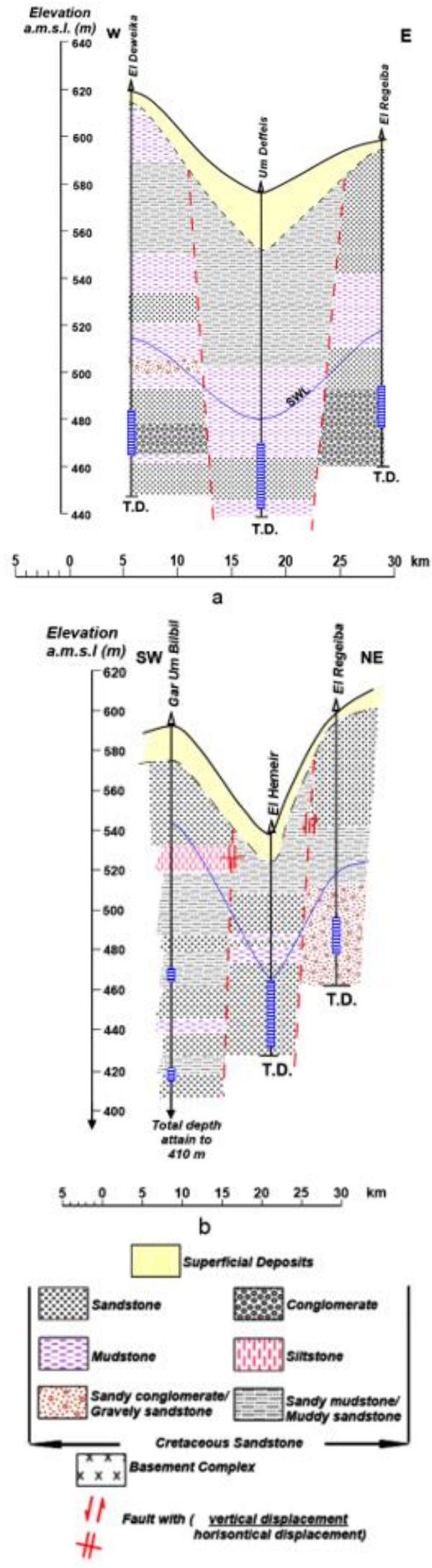

Figure 9. Ground elevations and thick superficial deposits
Table 1 summarizes the results of the pumping tests in the study area, classified for confined and unconfined aquifers. The thickness of the aquifers for the tested wells as an important factor in determining transmissivity show no contrast in range between confined and unconfined aquifers, it is generally vary from $16.77 \mathrm{~m}$ to $53.1 \mathrm{~m}$. Total drawdown in tested wells shows no clear variations between confined and unconfined aquifers, the large drawdown in Gafawa well at the astern border $(15 \mathrm{~m})$ is probably due to errors in well design and/or construction. The same thing is observed in the hydraulic parameters, there is a relative priority for unconfined aquifers in specific capacity. The close values of the hydraulic parameters of the confined and unconfined aquifers may be an indication to that the confining pressure in the confined aquifer is so weak, a character which occurs in the very small rising of water level above the saturation limits in many wells.

Table 1. Summary of the results of pumping tests

\begin{tabular}{|c|c|c|c|c|}
\hline \multirow{2}{*}{ Property } & \multicolumn{2}{|c|}{ Confined Aquifer } & \multicolumn{2}{|c|}{ Unconfined Aquifer } \\
\hline & $\min$ & $\max$ & $\min$ & $\max$ \\
\hline $\begin{array}{l}\text { Aquif. Thick. } \\
\text { (m) }\end{array}$ & 16.77 & 52 & 11.3 & 53.1 \\
\hline $\begin{array}{c}\text { Total Draw } \\
\text { down }(m)\end{array}$ & 0.63 & 15.10 & 0.026 & 5.79 \\
\hline$K(m / d)$ & 0.405 & 84.71 & 1.14 & 137 \\
\hline$T\left(m^{2} / d\right)$ & 13.20 & 2951 & 35.66 & 2844 \\
\hline$S$ & $\begin{array}{c}2.09 \times 10^{-} \\
5\end{array}$ & $\begin{array}{c}1.69 \times 10^{-} \\
1\end{array}$ & $\begin{array}{c}1.38 \times 10^{-} \\
2\end{array}$ & $\begin{array}{c}6.76 \times 10^{-} \\
1\end{array}$ \\
\hline $\begin{array}{c}\text { Sp. Capac. } \\
\left(m^{3} / d / m\right)\end{array}$ & $\begin{array}{c}5.69 \times 10^{-} \\
3\end{array}$ & $\begin{array}{c}9.28 \times 10^{-} \\
2\end{array}$ & $\begin{array}{c}6.33 \times 10^{-} \\
3\end{array}$ & $\begin{array}{c}7.38 \times 10^{-} \\
1\end{array}$ \\
\hline
\end{tabular}

(Abbreviations: Aquif. $=$ Aquifer, Sp.Capac. $=$ Specific Capacity, $\mathrm{K}=$ Hydraulic conductivity, $\mathrm{T}=$ Transmissivity, $\max =$ Maximum, $\min$ $=$ Minimum, $\mathrm{m}=$ Meter, $\mathrm{d}=$ Day)

Table 2. Assigning hydraulic conductivity to grain size [1]

\begin{tabular}{|c|c|c|c|}
\hline$\#$ & Hydraulic Conductivity $(\mathbf{m} / \mathbf{d})$ & Grain Size & $\mathbf{\%}$ \\
\hline 1 & $>100$ & Gravel & 2.60 \\
\hline 2 & $20-100$ & Coarse Sand & 47.40 \\
\hline 3 & $5-20$ & Medium Sand & 21.00 \\
\hline 4 & $1-5$ & Fine sand & 29.00 \\
\hline
\end{tabular}

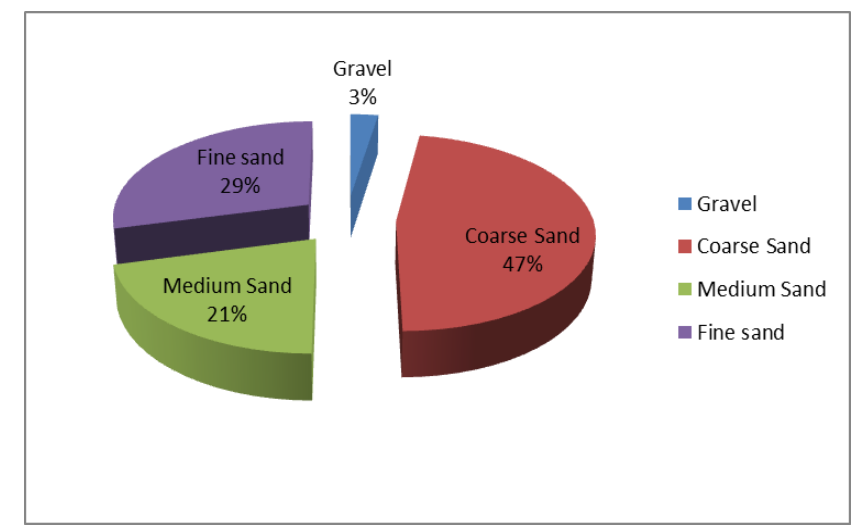

Figure 10. Assigning hydraulic conductivity to grain size

According to Bouwer [1] values of hydraulic conductivity from the tested wells are assigned to the grain size for 
material as shown in Table 2. From the table it is shown that the dominant size in the aquifer material is the coarse sand, followed by fine sand size, then medium sand and lastly the gravel size, where only one sample test show a conductivity of gravel size (> $100 \mathrm{~m} / \mathrm{d})$, (Figure 10). Based on Struckmeyer et al. [20], transmissivity is scaled into six classes: v. high, high, intermediate, low, v. low and imperceptible, Table 3. Accordingly, transmissivity obtained from the tested wells in the study area fills the upper three classes (Figure 11).

Table 3. Classification of transmissivity

\begin{tabular}{|c|c|c|c|c|c|}
\hline$\#$ & $\begin{array}{c}\mathbf{T} \\
\left(\mathbf{m}^{\mathbf{2}} / \mathbf{d}\right)\end{array}$ & class & Designation & $\begin{array}{c}\text { Gw. Supply } \\
\text { Potential }\end{array}$ & $\%$ \\
\hline 1 & $>100$ & 1 & Very High & $\begin{array}{c}\text { Regional } \\
\text { Importance }\end{array}$ & 26.3 \\
\hline 2 & $20-100$ & 2 & High & $\begin{array}{c}\text { Lesser Regional } \\
\text { Importance }\end{array}$ & 55.3 \\
\hline 3 & $5-20$ & 3 & Intermediate & $\begin{array}{c}\text { Local Water } \\
\text { Supply }\end{array}$ & 18.4 \\
\hline
\end{tabular}

GW. $=$ Groundwater

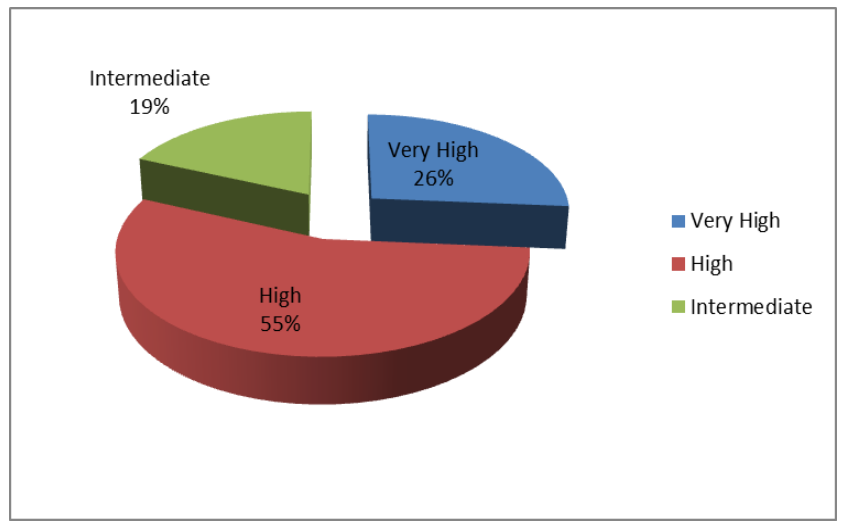

Figure 11. Classification of transmissivity

\subsection{Water balance in the study area}

Some efforts were made by many authors to quantify and estimate the groundwater balance in the area.

Some opinions were stated by Rodis et al. [7], judging with conditions in other regions in the world with similar climatic environments. He stated that recharge in semiarid central Kordofan may be about 5\% of annual rainfall, and evapotranspiration from the regional zone of saturation does not seem quantitatively important because the depth to this zone in most of the province is commonly more than $46 \mathrm{~m}$ below land surface. Also he stated that groundwater in the Nubian outlier of central Kordofan move laterally into surrounding Basement Complex rocks.

Strojexport [18] suggested that the share of the rainfall and other sources at forming dynamic reserves and circulations is variable in respect of climate and geological structures around and within the water bearing horizons. On the other hand and based on some observations they stated that hydrogeologically closed structures of limited extents are exist within the basin.

The utmost effort for mathematical simulations of groundwater dynamics in the area was made by Ginaya [5] which updated by the same author in the year 2011; there, the total storage, inflow, outflow and groundwater budget were estimated.
In spite of all, the mentioned attempts are considered just as formal or expressional; this assumption is based on the followings:

- The thickness of the saturated strata is not accurately determined where saturated zone is partially penetrated in plenty of wells and geophysical work conducted in the area is incomprehensive and insufficient to map the extents of these aquifers.

- No proper pumping tests have been performed for determining the hydraulic parameters so unacceptable representative parameters of aquifer characteristics are expected as a result of these tests.

- The abstraction from the basin is estimated statistically according to the number of the drilled wells that available for the author at that time, whereas the actual number is many times over that.

- The estimated yield of the operating wells usually depend on the well efficiency and pump efficiency, which affected by many designing and constructional factors.

Based on the above analysis, the water balance is not estimated in this study, but presently safe abstraction from the basin area is assumed. This assumption based on the intermittent observations on the water levels in boreholes conducted by different agencies, such as Groundwater Research Administration, Sudan. To confirm this assumption, only a simple comparison is performed between archived water levels and the measured water levels in recent drilled boreholes in the same area, these observations shows no change in water levels tenths of years.

\section{DISSCUSSION}

The complexity of groundwater fluxes in the study area is due to complex sources of recharge; linear divides of flow directions may indicate influence of the subsurface geologic structures. The distribution of groundwater fluxes discriminate two zones as northern and southern zones; these can be compared with the zones of aquifer classes demonstrated in Figure 7. The outflow at the western part of the basin may be follow structural features that extending into the surrounding Basement complex.

In spite of the cautions on the adequacy of the pumping test data, the resultant values are considered as suitable approximations for the hydraulic characteristics of the aquifer system. For proper determination of the aquifers properties, disciplined aquifer tests in full penetrated and ideally designed well sets are required.

Regarding Um Deffeiss- El Himeir area a detailed work is necessary to obtain a reasonable interpretation for the irregular state. In the same manner, high regulated work and precisely performed process in the future is required to answer the question of the water balance in the area.

\section{CONCLUSION}

The importance of En Nuhud Basin is coming from that it is the only source of water supply in a wide, densely populated area. The groundwater fluxes show high complexity due to various recharge sources; from the boundary and from local sources over the basin; in addition 
to the outflow at the western part of the basin. Hydraulic parameters of the aquifer system show good characteristics of these aquifers. Earnest and diligent research to evaluate the hydrogeological conditions and to estimate groundwater potentiality of the basin is needed for safe use. Further geophysical and hydrogeological investigations and deep drilling can serve for proper evaluation of the subsurface hydrogeological conditions. Remote sensing may be beneficial in mapping the geomorphological features and the probable sources of surface recharge to the basin.

\section{ACKNOLEDGEMENT}

Acknowledgement is to all institutions, agencies and individuals who help anyway in completing this work.

\section{REFERENCES}

[1] Bouwer H. (1978). Groundwater Hydrology. Mc-Graw Hill, New York, NY, pp. 480.

[2] Elmansour AA. (2016). Assessment of the Groundwater of En Nuhud Basin, Sudan, PhD Thesis, University of West Kordofan, Sudan, pp. 47-115.

[3] Geological Map of Sudan (1981). Prepared by G.M.R.D. Khartoum- Sudan, the Assistance of R.S.C. GeddahKingdom of Saudi Arabia and Collaboration of the B.R.G.M. Orleans France.

[4] Ginaya MA. (2001). Hydrogeological investigation of en nuhud basin, west kordofan state, Sudan. MSc Thesis, Department of Geology and Mining, College of Natural Resources and Environmental Studies, Juba University, Sudan, pp. 70-74.

[5] Ginaya MA. (2011). Updating of groundwater conditions of ennahud basin, North Kordofan, Sudan. $\mathrm{PhD}$ Thesis, Institute for Energy \& Earth Sciences, Ministry of Sciences \& Technology, Sudan, pp. 93-102.

[6] Karkanis BG. (1966). Hydrochemical facies of grounwater in the western provinces of Sudan. MSc. Thesis, Graduate College, University of Arisona. https://hdl.handle.net/10150/191466
[7] Rodis HG, Hassan A, Wahadan L. (1964). Groundwater geology of Kordofan province, bulletin No. 14, Ministry of Mineral Resources, Geological Survey Department, Khartoum, Sudan. https://doi.org/10.3133/wsp1757J

[8] Strojexport (1971-1972). Parametrical Measurements at Boreholes, Appendix 1, pp. 7-8.

[9] Strojexport (1971-1972). Log description with Geophysical Parameters, Appendix 4, pp. 30-100.

[10] Strojexport (1971-1972). Catalog of Gravity Values, Appendix 6, pp. 1-47.

[11] Strojexport (1972). Groundwater Research, SW part of Kordofan, Second Stage, Final Report, Praque, pp. 7-12.

[12] Strojexport (1973). Preliminary interpretation of the first part of the third stage geophysical investigation in the western and central part of Kordofan Province in the Sudan. The Foreign Trade Corporation Strojexport, PRAHA 1, Czechslovakia, pp. 23-31.

[13] Strojexport (1975). Geophysical Investigation of Hydrogeological Structures, Western Part of Kordofan Province, pp. 11-15.

[14] Strojexport (1975). Parametrical Measurements at Boreholes, Appendix 1, pp. 1-14.

[15] Strojexport (1975). Geoelectric Resistivity Sections with Gravity and Magnetic Curves, Appendix 2, pp. 239.

[16] Strojexport (1975). Log Description of Boreholes, Appendix 5, pp. 4-10.

[17] Strojexport (1975). Parametrical Analysis, Appendix 7, pp. 6-7.

[18] Strojexport (1976). Interpretative Gravity Profiles and Geoelectric Resistivity Sections Including Gravity and Magnetic Graphs, Appendix 4, pp. 6-7.

[19] Strojexport (1976). Geophysical investigations of groundwater structures, western part of Kordofan province an eastern part of Darfur Province, fourth stage. Strojexport Foreign Trade Corporation for Export and Import, Praque, Czechoslovakia, pp. 11-29.

[20] Struckmeyer WF, Margat J. (1995). Hydro-geological maps, a guide and a standard legend. International Association of Hydrogeologists, Hannover, Heise, pp. 177. 